\title{
A múltipla Pequena África no Rio de Janeiro: perspectivas reflexas de negros e judeus
}

\section{The diverse Small Africa in Rio de Janeiro: reflective perspectives of Black and Jewish people}

\section{Simone Pondé Vassallo}

Doutora em Antropologia Social pela École des Hautes Études en Sciences Sociales (EHESS) de Paris. É professora do Departamento de Antropologia da Universidade Federal Fluminense (UFF) e pesquisadora do Núcleo de Antropologia das Artes, Ritos e Sociabilidades Urbanas (NARUA-UFF Artes): imagens, narrativas e sonoridades. Atua nas áreas de patrimônio cultural e Antropologia urbana e desenvolve pesquisa sobre os processos de patrimonialização da cultura afro-brasileira na região portuária do Rio de Janeiro.

\section{Daniel Bitter}

Professor do Departamento de Antropologia da Universidade Federal Fluminense (UFF). Pesquisador do Núcleo de Antropologia das Artes, Ritos e Sociabilidades Urbanas (NARUA-UFF Artes): imagens, narrativas e sonoridades e do Núcleo Antropologia da Memória: coleções, museus e patrimônios, da Universidade Federal do Rio de Janeiro (UFRJ). Publicou o livro A bandeira e a máscara: a circulação de objetos rituais nas folias de reis. Rio de Janeiro: 7 letras; CNFCP/Iphan, 2010.

\section{Resumo}

Neste artigo, pretendemos pensar as dinâmicas de produção de narrativas e experiências contemporâneas acerca do território imaginário que veio a ser conhecido como a Pequena África, no Rio de Janeiro, tentando compreender como elas entrelaçam pessoas e lugares, muitas vezes de forma tensa e disputada. Partimos da perspectiva de Michel Agier, para quem a cidade é um significante vazio cujos múltiplos e possíveis sentidos são elaborados situacionalmente pelos atores sociais. Nesse sentido, entendemos que a Pequena África não possui uma definição rígida e pré-definida mas, ao contrário, é sempre aberta à pluralidade de significados e entendimentos atribuídos pelos diferentes indivíduos e grupos que dela se apropriam. Para tanto, iremos analisar algumas narrativas e práticas e seus principais protagonistas, a saber: as ações de Gracy Mary Moreira em torno das memórias de sua bisavó, Tia Ciata; a luta de lideranças negras da Comissão da Pequena África pela história de um cemitério de africanos escravizados; 
e as práticas de um grupo de músicos judeus denominado Rancho Praça Onze Klezmer Carioca, que procura recriar a memória da vida judaica na região.

Palavras-chave: Pequena África, Movimento Negro, Judeus, Sociabilidade Carioca, Rio de Janeiro.

\section{Abstract}

In this article, we intend to think about the dynamics of production of contemporary narratives and experiences about the imaginary territory that came to be known as Little Africa in Rio de Janeiro, trying to understand how they intertwine people and places, often in a tense and disputed way. We start from the perspective of Michel Agier (2011), for whom the city is an empty signifier whose multiple and possible meanings are elaborated situationally by the social actors. In this sense, we understand that Little Africa does not have a rigid and predefined definition but, instead, is always open to the plurality of meanings and understandings attributed by the different individuals and groups that appropriated it. To do so, we will analyze some narratives and practices and their main protagonists, namely: the actions of Gracy Mary Moreira around the memories of her great-grandmother Tia Ciata; the black leadership struggle of the "Little Africa Commission" for the history of a cemetery of enslaved Africans; the practices of a group of jewish musicians called Rancho Praça Onze Klezmer Carioca, which seeks to recreate the memory of Jewish life in this region.

Keywords: Little Africa, Black Movement, Jews, Carioca Sociability, Rio de Janeiro.

\section{INTRODUÇÃO}

Este artigo se propõe a refletir sobre os processos de produção e reconfiguração dos espaços urbanos, pensando a cidade a partir de um ponto de vista processual que privilegie as tensões e as transformações que a atravessam $^{1}$. Para tanto, procuraremos pensar as dinâmicas de produção de narrativas

Agradecemos a contribuição de Fillipe Alexandre Oliveira Alves, discente do Bacharelado em Ciências Sociais da UFF e bolsista do Programa Institucional de Bolsas de Iniciação Científica (Pibic/UFF). 
e experiências contemporâneas acerca do território imaginário que veio a ser conhecido como a Pequena África no Rio de Janeiro, tentando compreender como elas entrelaçam pessoas e lugares, muitas vezes de forma tensa e disputada. Partimos da perspectiva de Michel Agier (2011), para quem a cidade é um significante vazio cujos múltiplos e possíveis sentidos são elaborados situacionalmente pelos atores sociais. Nesse sentido, entendemos que a Pequena África não possui uma definição rígida e pré-definida mas, ao contrário, é sempre aberta à pluralidade de significados e entendimentos atribuídos pelos diferentes indivíduos e grupos que dela se apropriam.

A chamada Pequena África - expressão atribuída a Heitor dos Prazeres por Roberto Moura (1995) - ganhou notoriedade nas últimas décadas moldando representações sobre a presença afrodescendente e de outros grupos na região central da cidade do Rio de Janeiro. Uma diversidade de categorias sociais tem reivindicado uma ligação histórica e existencial com este território, seja como forma de "resistência cultural" ou de expressão de pertencimentos étnicos e sociais. Ao que tudo indica, a Pequena África se refere a uma ampla região da cidade que se estende da Cidade Nova à região portuária. No entanto, acreditamos que suas fronteiras e seu conteúdo sejam fluidos e erigidos situacionalmente.

A Zona Portuária do Rio de Janeiro - que engloba os bairros Saúde, Gamboa e Santo Cristo - vem sendo alvo de impactantes projetos de intervenção no espaço urbano desde o início do século XX, com a reforma do então prefeito Pereira Passos. Essas intervenções culminam com o projeto Porto Maravilha de revitalização (2009-2016), que busca adequar a cidade aos grandes eventos que ocorrem nesse período, como a Copa do Mundo de Futebol (2014) e os Jogos Olímpicos (2016). Mas, ao longo do século XX, a mesma região também é lembrada por cronistas, folcloristas e demais pesquisadores pela forte presença de diversas expressões culturais e religiosas afrodescendentes e, em particular, por sua importância na criação do samba como gênero musical (GONÇALVES, 2003, 2013). Tais relatos dão visibilidade para alguns dos seus principais protagonistas, como os imigrantes baianos que ali se estabeleceram no período do pós-abolição, entre fins do século XIX e início do $\mathrm{XX}$, criando seus espaços de moradia, lazer, sociabilidade e religião. Vale notar 
que muitos judeus que imigraram para o Rio de Janeiro desembarcavam nessa mesma região portuária na qual, frequentemente, já encontravam familiares e amigos que os levavam para a Praça Onze, onde formariam o bairro judeu.

Na década de 1980, com o fim da ditadura militar e a reorganização do movimento negro, os relatos sobre as expressões culturais negras da região portuária são retomados e ressignificados por militantes negros, pesquisadores e representantes do poder público. Os imigrantes baianos e suas práticas culturais do período pós-abolição se tornam símbolos de resistência à dominação e expressões da vitalidade e da importância da cultura afro-brasileira. As ressignificações dessas práticas afrodescendentes são fortemente influenciadas pela publicação do livro Tia Ciata e a Pequena África no Rio de Janeiro, de Roberto Moura, em 1983 (VASSALLO, 2015). Nesta obra, o autor dá ampla visibilidade à atuação de Tia Ciata (Maria Hilária Batista de Almeida, 1854-1924) e outras tias baianas em torno da sociabilidade afro-baiana e carioca que se organizava em torno do samba, do candomblé, do trabalho na estiva e de demais expressões culturais negras. É digno de nota que Tia Ciata tenha residido em diversos endereços espalhados pela região central, incluindo a Praça Onze e as imediações da Pedra do Sal, na Saúde. O termo Pequena África, que antes do livro de Moura não aparecia nas produções escritas, adquire grande circulação e passa a simbolizar um território negro de resistência cultural. Tia Ciata se torna a principal personagem desse movimento, mas a memória de outros atores é também trazida à tona.

A partir dos anos 2000, em meio às tensões provocadas pelos novos projetos de revitalização da região portuária, como o Plano Porto do Rio (20012008) e o Projeto Porto Maravilha (2009-2016), a expressão Pequena África é reapropriada por diversos indivíduos e grupos que afirmam o pertencimento a esse território e lhe imprimem diferentes significados. Nesse processo, observamos também a presença de coletivos que reivindicam pertencimentos étnico-raciais não negros. Isso ocorre porque a Cidade Nova, por meio de seus dois pontos centrais - a antiga Praça Onze e o Campo de Santana -, foi palco de uma intensa vida cosmopolita e intercultural, abrigando imigrantes portugueses, espanhóis, italianos, ciganos, judeus, além de significativa população 
afrodescendente. Essa fração da Pequena África foi, sem dúvida, território em que se manifestou uma interação do tipo porosa (CARVALHO, 2013), sendo um marco simbólico de encontros e da produção de certos gêneros musicais, tais como maxixe, samba e choro, entre outros, que se tornariam emblemáticos da identidade carioca. A presença de judeus refugiados do Leste Europeu é particularmente notória no entorno da antiga Praça Onze, onde se fixaram nas primeiras décadas do século XX. Ali, ao lado da comunidade negra e de outros imigrantes, os judeus desenvolveram uma intensa vida social e cultural, deixando marcas de seus costumes na cultura carioca.

Neste artigo, propomo-nos a observar como ocorrem algumas dessas reapropriações contemporâneas da Pequena África. Partiremos da análise de algumas narrativas e práticas e seus principais protagonistas, a saber: as ações de Gracy Mary Moreira em torno das memórias de sua bisavó Tia Ciata; a luta de lideranças negras da "Comissão da Pequena África" pela história de um cemitério de africanos escravizados; as práticas de um grupo de músicos judeus denominado Rancho Praça Onze Klezmer Carioca, dirigido por Ricardo Goldfeld Szpilman, que procura celebrar os imaginários encontros entre Tia Ciata e a comunidade judaica na Praça Onze, nas primeiras décadas do século XX.

Uma das motivações para a escrita conjunta deste artigo foi a descoberta de que situações empíricas muito distintas, de certo modo, convergiam para um mesmo ponto: a Pequena África. Parece sintomático que diferentes grupos venham reivindicar uma relação particular com esse território, desvelando suas memórias subterrâneas. Um dos objetivos deste texto é colocar em diálogo pesquisas desenvolvidas de forma independente e que, quando comparadas e contrastadas, oferecem uma perspectiva original. No entanto, cada um destes contextos e seus respectivos atores aciona representações próprias deste território, ora convergentes, ora divergentes, cada qual com características singulares cujas nuances procuramos explorar aqui. No caso de Gracy Mary e das lideranças envolvidas com a Comissão da Pequena África, trata-se de atores que hoje possuem uma forte presença e atuação na região e são muito empenhados em trazer à tona as memórias negras ali contidas, ainda que de maneiras bastante diferenciadas. 
Já no caso do Rancho Praça Onze Klezmer carioca, é digno de nota que desde seu surgimento, em 2013, suas ações parecem se consolidar como um projeto permanente de revivificação da memória da vida judaica na Praça Onze. Por meio da música, pesquisa e outras atividades desenvolvidas pelo grupo, uma geração de judeus tem elaborado um senso de pertencimento singular e contribuído para uma percepção mais complexa da cultura carioca. Gostaríamos de destacar o protagonismo de Gracy Mary Moreira e Ricardo Szpilman, nossos principais interlocutores, e expressamos nossa gratidão por sua generosa disposição em manter diálogos conosco.

Assim sendo, entendemos que com suas práticas individuais e coletivas esses atores sociais constroem identidades e pertencimentos e atribuem sentidos próprios a si mesmos e às suas experiências e vivências do urbano. Através de suas ações cotidianas, produzem ao seu modo a Pequena África ao mesmo tempo em que produzem a si próprios como sujeitos dessas histórias.

Partindo das ideias de Margaret Rodman (2008), pensamos os lugares como socialmente construídos pelas pessoas que os frequentam, e não como quadros rígidos e pré-determinados em que ocorrem as ações. As localidades não são meras reproduções de uma estrutura dada de antemão, elas são também produzidas - e com isso permanentemente modificadas - pelos que as reivindicam para si (APPADURAI, 1996). Nesse sentido, acreditamos que não há uma Pequena África única, pré-definida e atemporal, muito embora esta seja ocasionalmente revestida de uma tonalidade mítica. Ao contrário, ela está em permanente construção, sendo feita e refeita, produzida e performatizada de diferentes maneiras, em função do contexto e dos atores envolvidos em cada situação observada. Inspirados em Michel Agier (2011), nos propomos a pensar a cidade não a partir de uma definição a priori, fixa e externa aos agentes sociais, mas sim tendo por base a sua dimensão processual, dinâmica e por isso sempre múltipla e em transformação. Com isso, nosso olhar se desloca dos lugares para as pessoas que os vivenciam e lhes atribuem sentidos, da observação de objetos para a análise de situações (AGIER, 2011).

Acreditamos que a Pequena África é multivocal (RODMAN, 2008), na medida em que abriga diferentes sujeitos, vozes e definições. Ela pode incluir 
ativistas negros, músicos judeus, ciganos, imigrantes, lideranças religiosas, moradores, gestores públicos, pesquisadores, dentre outras tantas possibilidades. Pode-se acrescentar que a região central foi, de fato, palco de intensos encontros entre distintas categorias e classes sociais, promovendo-se uma ampla circulação entre ricos e pobres, erudito e popular. Seus significados, portanto, estão sempre em disputa e os conflitos parecem se tornar ainda mais intensos na atualidade, devido à centralidade adquirida pela região portuária com os processos de "revitalização".

Os atores sociais observados aqui procuram trazer à tona memórias subterrâneas (POLLAK, 1992) de uma cidade habitada por negros e outros grupos subalternizados, do passado e do presente, tais como ciganos, judeus, muçulmanos e demais imigrantes invisibilizados pelas grandes narrativas da nação e pelos sucessivos projetos de urbanização. Nesse sentido, as localidades são também lugares políticos (RODMAN, 2008). Por meio da afirmação de laços primordiais com o território da Pequena África, lideranças negras reivindicam poder, participação e reconhecimento, e músicos judeus constroem uma judeidade carioca própria, valorizando seu vínculo com a cultura afro-brasileira.

A essa altura, é oportuno observar que há muitas conexões entre as diásporas negra e judaica, incluindo o fato de estes povos terem sido vítimas de crimes bárbaros contra a humanidade. Negros e judeus em muitas partes do mundo têm lutado por uma justa reparação por esses crimes e têm resistido a uma recente onda de negacionismo ou revisionismo de suas trajetórias históricas, visando minimizar os efeitos da opressão. O que permitiu a convivência mais ou menos harmoniosa entre esses grupos em torno da Tia Ciata foi a condição de pobreza material, de subalternização, de perseguição e de vítimas de discriminação racial. É verdade, entretanto, que no Brasil, em função de sua ascensão social, os judeus tenderam, com o passar do tempo, a serem assimilados à abrangente categoria dos brancos, o que não deixa de ser um incômodo para muitos. Como bem observou Monica Grin (2009), dada a distância social entre judeus e negros no Brasil, as situações de contato entre eles foram raras. Entretanto, a Praça Onze, um dos pontos nevrálgicos da Pequena África, pode ter sido um destes espaços intersticiais de encontros que, no argumento 
de Bruno Carvalho (2013), foram marcados pela ambiguidade e contradição entre porosidade cultural e distância socioeconômica.

\title{
LIDERANÇAS NEGRAS NA PEQUENA ÁFRICA
}

\section{A Pequena África e a Pedra do Sal}

De acordo com o livro de Roberto Moura (1995), o bairro da Saúde, debruçado sobre o cais do porto, consistia num atraente local de moradia para os imigrantes baianos no período do pós-abolição que ali buscavam trabalho na estiva, abriam suas casas de santo, faziam suas rodas de samba e seus ranchos carnavalescos. As vizinhanças da Pedra da Prainha, depois conhecida como Pedra do Sal, tornariam-se locais de intensa sociabilidade entre africanos remanescentes do período do tráfico negreiro - e baianos. Com as reformas urbanísticas de Pereira Passos, essas densas redes de sociabilidade e suas expressões culturais se expandem para a Cidade Nova. Segundo o autor,

\begin{abstract}
a partir da ocupação da Cidade Nova pela gente pobre deslocada pelas obras [promovidas por Pereira Passos], que a superpovoava na virada do século, a praça [Onze] se tornaria ponto de convergência desses novos moradores, local onde se desenrolariam os encontros de capoeiras, malandros, operários do meio popular carioca, músicos, compositores e dançarinos, dos blocos e ranchos carnavalescos, da gente do candomblé ou dos cultos islâmicos dos baianos, de portugueses, italianos e espanhóis (MOURA, 1995, p. 58).
\end{abstract}

As tias baianas, lideradas por Tia Ciata, "eram os grandes esteios da comunidade negra, responsáveis pela nova geração que nascia carioca, pelas frentes do trabalho comunal, pela religião" (MOURA, 1995, 92). Em suas casas, "as grandes figuras do mundo musical carioca, Pixinguinha, Donga, João da Baiana, Heitor dos Prazeres, surgem ainda crianças naquelas rodas onde aprendem as tradições musicais baianas a que depois dariam uma forma 
nova, carioca" (MOURA, 1995, p. 102). E a casa de Tia Ciata, na Praça Onze, era a capital da Pequena África.

Apesar de Roberto Moura destacar a centralidade tanto da Pedra do Sal quanto da Praça Onze na composição da Pequena África, é a primeira que adquire mais relevância nas ações de diversas lideranças negras contemporâneas, ainda que as referências à Praça Onze também se façam presentes. Assim, um dos principais efeitos da publicação do livro de Moura é o tombamento da Pedra do Sal pelo Instituto Estadual do Patrimônio Cultural (INEPAC) no ano seguinte (1984), que ocorre a partir da confluência de ações do movimento negro e do Governo do Estado do Rio de Janeiro (SOARES, 1999), que na época tinha Darcy Ribeiro como vice-governador e secretário estadual de cultura. Um dos principais argumentos do dossiê de tombamento da Pedra do Sal consiste no fato de ela ser "o mais antigo monumento que se pode vincular à história do samba carioca" e "um precioso monumento histórico das manifestações culturais negras da cidade do Rio de Janeiro" (INSTITUTO ESTADUAL DO PATRIMÔNIO CULTURAL, 1984). Poucos anos depois, o Centro Cultural José Bonifácio é criado a centenas de metros dali e se transforma rapidamente num centro de referência da cultura afro-brasileira ${ }^{2}$, contribuindo para a consolidação da africanidade desse território.

A partir dos anos 2000, intensificam-se por parte da prefeitura e do setor privado os interesses imobiliários na região, que resultam na criação de dois sucessivos projetos de "revitalização" para a área, o Plano Porto do Rio (20012008) e o Projeto Porto Maravilha (2009-2016), ambos realizados a partir de parcerias público-privadas. Esses projetos impactam profundamente a localidade, atraindo novos atores sociais e gerando intensos conflitos em torno de seus usos e narrativas.

Nesse contexto, o imaginário em torno da Pequena África torna-se mais uma vez altamente relevante para diversas lideranças negras, que o investem de múltiplos significados. No início dos anos 2000, como decorrência de tensões

\footnotetext{
2 O centro cultural foi criado graças à atuação de moradores da Saúde e representantes da prefeitura, e é gerido pela Secretaria Municipal de Cultura. Desde 1990 a sua direção está a cargo de lideranças do movimento negro.
} 
imobiliárias geradas pelo Plano Porto do Rio, um grupo de moradores do sopé da Pedra do Sal reivindica a identidade de remanescente do Quilombo Pedra do Sal, obtendo em 2005 o reconhecimento da Fundação Palmares. Os integrantes do quilombo se consideram herdeiros e perpetuadores das tradições e do modo de vida da comunidade baiana do início do século XX (GUIMARÃES, 2014). Suas narrativas giram em torno do que chamam de tríade sal-samba-santo (MATTOS; ABREU, 2012), que tem por referência o trabalho na estiva, o samba e demais expressões culturais afro-brasileiras, bem como as religiões de matriz africana, que estruturam suas representações da Pequena África e reelaboram ao seu modo a obra de Moura (VASSALLO, 2015). Nas ações dos integrantes do quilombo e de seus apoiadores, a Pedra do Sal se consolida como principal símbolo dessa Pequena África por eles performatizada e encarna as suas principais características.

O Projeto Porto Maravilha de "revitalização", iniciado em 2009, mobilizou alguns bilhões de reais e visou a adequação da Zona Portuária aos grandes eventos que a cidade iria receber. A região adquiriu centralidade na grande imprensa, nas ações da prefeitura e nos investimentos da iniciativa privada, o que favoreceu a chegada de novos moradores e agentes culturais e intensificou as disputas em torno de seus espaços físicos, apoios financeiros, usos e representações. Os veículos oficiais de comunicação da Prefeitura enfatizavam o aspecto "degradado" e "atrasado" da área (GUIMARÃES, 2014) e assim justificavam a necessidade da sua "modernização" por meio de uma retórica norteada pela ideia de um futuro supostamente redentor. Com esse intuito, imensas escavadeiras alteravam drasticamente a sua paisagem física, seus usos e suas memórias, impedindo o acesso a importantes vias, destruindo edificações, revolvendo o solo e trazendo inesperadamente vestígios de um passado até então pouco conhecido, como atracadouros, trapiches e armazéns que testemunharam as atividades portuárias dos tempos do Império e da escravidão.

Nesse contexto, e em resposta às ações da prefeitura que negligenciavam as histórias locais, diferentes indivíduos e coletivos começaram a enfatizar o passado da localidade e a promover atividades culturais que o performatizavam. Para muitos deles, a região portuária encarna um lugar mítico de origem do 
samba, da capoeira e de outras expressões culturais afro-brasileiras, das religiões de matriz africana, da história da cidade. Algumas de suas ações conseguiram obter um pequeno apoio de setores do Estado voltados para a preservação patrimonial, como o Instituto do Patrimônio Histórico e Artístico Nacional (Iphan), o Instituto Rio Patrimônio da Humanidade (IRPH) e setores da própria Companhia de Desenvolvimento Urbano da Região Portuária (CDURP), criada pela prefeitura para gerir o projeto de "revitalização".

Gracy Mary Moreira ${ }^{3}$ é uma das lideranças negras que nos últimos anos conseguiu desenvolver um projeto cultural na região portuária e rememorar o seu passado, fundando a Casa de Tia Ciata. Gracy atendia ao pedido de seu falecido pai, o sambista músico e compositor Bucy Moreira, neto de Tia Ciata, para que seus filhos não deixassem a memória de sua avó e da Pequena África morrer. Com esse intuito, ela e outros familiares fundaram em 2007 a Organização Remanescentes de Tia Ciata (ORTC), cujas ações culminam com a abertura da casa mencionada acima, nas proximidades da Pedra do Sal. Para Gracy, a instituição é um espaço de memória destinado a contar ao público quem foi essa mulher, "matriarca do samba", cuja casa se tornou a "capital da Pequena África”, nas suas próprias palavras (MULTIPLICANDO..., 2018).

De acordo com o site da instituição, "Hilária Batista de Almeida, conhecida como Tia Ciata, é uma das figuras mais influentes da cultura negra carioca do início do século XX. Em sua casa, diversas expressões culturais, artísticas e religiosas da cultura negra, perseguidas na época, encontraram um espaço de liberdade e manifestação. Referência até os dias de hoje, Tia Ciata empreendeu há mais de 100 anos ações sociais e movimentos alinhados com pautas debatidas atualmente como o feminismo, racismo e tolerância religiosa. (...) Ela é certamente figura essencial no processo de formação da nossa identidade nacional" (disponível em https://www.tiaciata.org.br/home, acessado em 12/01/19).

\footnotetext{
Gracy Mary Moreira tem 54 anos e é formada em Gestão de Recursos Humanos. É diretora de produção cultural e envolvida em diversas associações e atividades de promoção da cultura afro-brasileira, principalmente do samba. Na atualidade, dedica-se à valorização das memórias de sua bisavó Tia Ciata, da Pequena África e do samba por meio das diferentes ações que promove na Organização Cultural Remanescentes de Tia Ciata (ORTC), da qual é presidenta. As atividades incluem mesas-redondas, rodas de samba, cortejos e circuitos a pé pelo território da Pequena África.
} 
Inspirando-se no imaginário da Pequena África difundido pela obra de Moura, essas representações enfatizam a centralidade da tia baiana. Nelas, Ciata é descrita como uma referência fundamental para a cultura negra, as religiões de matriz africana, as mulheres negras, a cidade do Rio de Janeiro e a identidade brasileira como um todo, e sua casa encarna um local emblemático da resistência cultural feminina e afro-brasileira.

O site da instituição traz também a memória do pai de Gracy:

Mãe-de-santo afamada, Tia Ciata festejava seus orixás, sendo famosas suas festas de São Cosme e Damião e de sua Oxum, Nossa Senhora da Conceição. Nas festas suas habilidades de partideira a destacavam nas rodas de partido-alto, e seu neto Bucy Moreira aprendeu com ela o segredo do "miudinho", uma forma de sambar de pés juntos que exige destreza e elegância, no qual Ciata era mestra. Logo após a cerimônia religiosa, antecedida por uma missa cristã, músicos e capoeiras amigos da casa armavam um pagode com violões, pandeiros, ganzás e muito samba. Tia Ciata [...] [promovia] em sua casa saraus com chorões e bailes amaxixados no salão da frente, sem esquecer um bom samba lá no fundo do quintal, sempre com uma cerimônia de candomblé encerrando as festividades (BIOGRAFIA, 2010).

Assim, memórias familiares se mesclam às públicas de Tia Ciata e da Pequena África, que foram se consolidando por meio da atuação de escritores, pesquisadores, lideranças negras e outros atores.

A abertura da Casa de Tia Ciata não foi fácil, fazia anos que Gracy Mary procurava levar a sede da sua organização para a região portuária. Em 2016 ela conseguiu finalmente inaugurar o centro cultural, graças à obtenção de um espaço cedido pela prefeitura e reivindicado por diversos agentes culturais. Durante a realização do Projeto Porto Maravilha, os espaços físicos da Zona Portuária que pertenciam ao poder público foram intensamente disputados por diferentes grupos de atores sociais. O projeto gerou conflitos entre os que se consideram moradores antigos - e reivindicam prioridade na distribuição dos recursos públicos - e os acusados de serem recém-chegados e oportunistas. Os primeiro são acusados de bairristas e os segundos, de paraquedistas. Apesar da recente presença de Gracy e sua instituição na região portuária ser 
passível de críticas das lideranças que se consideram moradores antigos, o fato de ela ser bisneta de Tia Ciata lhe confere uma enorme legitimidade diante destes últimos, que a chamam carinhosamente de "Ciatinha" e apoiam a sua permanência.

Segundo Gracy Mary, "essa é a minha história e eu vou continuar contando, não preciso de ninguém para contar por mim” (CULTNE DOC..., 2018). E é neste sentido que devemos compreender as diversas ações empreendidas por ela no seu centro cultural, como a Roda de Samba da Cabaça - promovida mensalmente - e o roteiro Caminhos de Tia Ciata, que passa por importantes locais frequentados por ela, "da Pedra do Sal à Praça Onze, onde ela iniciou seu caminho cercado de tradições, realizações, religiosidade, quitutes e samba" (CAMINHOS..., 2015). A casa também organiza o Cortejo da Tia Ciata que, em 20 de novembro, Dia da Consciência Negra, parte da estátua de Zumbi dos Palmares, na Praça Onze, até o Cais do Valongo, na região portuária: "O Cortejo da Ciata é sobretudo uma celebração, uma homenagem à grande Tia Ciata, das primeiras rodas de samba, dos ritos e dos doces, das baianas, da Praça Onze, do quintal com Pixinguinha, Donga, João da Baiana" (CORTEJO..., 2018). O cortejo coloca lado a lado Tia Ciata e Zumbi, enfatizando as lutas e a resistência de ambos. Parte dessas iniciativas conta com um pequeno apoio da Secretaria Municipal de Cultura e da Superintendência Regional do Iphan.

Por meio dessas ações, Gracy Mary produz mediações entre passado e presente, coloca em relação temporalidades e pessoas, o período pós-abolição e a contemporaneidade do projeto de "revitalização", a sua bisavó Tia Ciata, seu pai Bucy Moreira e ela própria. Cria uma continuidade narrativa lá onde o tempo e a paisagem urbana haviam produzido rupturas e apagamentos. Presentifica essa história ao inserir-se nela e colocar-se como aquela que a perpetua. Com isso, afirma a centralidade do seu próprio protagonismo e os seus pertencimentos familiares e territoriais. Ao fazê-lo, Gracy produz ao seu próprio modo a região da cidade hoje lembrada como Pequena África, ao mesmo tempo em que produz a si mesma como sujeito dessa história, narrada no tempo presente e na primeira pessoa. 
Apesar da ênfase na participação das lideranças afro-brasileiras, a Pequena África de Gracy Mary é também um local de encontros multiétnicos entre pessoas que compartilharam uma mesma situação de precariedade e preconceito no início do século XX. Para ela, a casa de Tia Ciata reunia também islâmicos, judeus, ciganos, além dos próprios negros, "aquelas pessoas que lutavam, aquelas minorias que eram marginalizadas" (CULTNE DOC..., 2018).

Em todas essas narrativas, ainda que de diferentes maneiras, Tia Ciata e a Pedra do Sal emergem como principais referências que estruturam os poderosos símbolos evocados pela Pequena África. Seus significados giram em torno de uma sociabilidade festiva que perpassaria as expressões culturais afro-brasileiras como o samba, os ranchos, o candomblé e a capoeira, e da resistência dos seus principais protagonistas a diferentes formas de dominação e opressão.

\section{A Pequena África e a reparação pela memória}

A partir dos anos 2000, outra narrativa sobre a Pequena África ganha visibilidade e amplia os seus contornos espaciais, temporais e semânticos. Trata-se das representações que giram em torno do tráfico transatlântico negreiro e da escravização. Elas traduzem localmente uma série de ações internacionais ocorridas nas últimas décadas, como o Projeto Rota do Escravo (RDE), criado pela Organização das Nações Unidas para a Educação, a Ciência e a Cultura (Unesco) nos anos 1990 com o intuito de desenvolver um turismo de memória em diferentes locais diretamente relacionados ao tráfico transatlântico negreiro e à escravização. Também podemos mencionar a descoberta de cemitérios de escravizados nos EUA e as recentes construções de museus, memoriais e monumentos que fazem referência direta à escravidão negra, criados em importantes cidades da Europa e das Américas. Um importante marco dessas novas representações ocorreu em 2001, em Durban, durante a Conferência da Organização das Nações Unidas (ONU) contra o racismo, a xenofobia e intolerâncias correlatas, quando a escravização e o tráfico transatlântico negreiro foram classificados como crimes contra a humanidade, em analogia ao holocausto judeu (BRASIL, 2001). O reconhecimento por parte da ONU favoreceu a grande difusão de novas representações da escravidão 
ancoradas numa nova moralidade e propiciou pedidos de reparação simbólica e financeira por parte de organizações negras em várias partes do mundo.

Na região portuária, as memórias da escravidão são fortalecidas a partir de 2011, com o desenterramento do Cais do Valongo, nas imediações da Pedra do Sal, na Saúde. De acordo com os arqueólogos responsáveis pela escavação, pelo Cais teriam desembarcado ao menos 1 milhão de africanos escravizados nas primeiras décadas do século XIX, daí a sua relevância. A partir da atuação de lideranças do movimento negro, pesquisadores universitários e alguns setores do poder público, o Cais tornou-se o maior símbolo do tráfico transatlântico negreiro fora da África (VASSALLO; CICALO, 2015) e em 2017 foi reconhecido pela Unesco como patrimônio da humanidade.

Já em 1996, havia sido acidentalmente encontrado o Cemitério dos Pretos Novos, na Gamboa, destinado ao enterramento de africanos escravizados entre cerca de 1770 e 1830. No local foi criado o Instituto dos Pretos Novos, com o intuito de trazer à tona a memória silenciada da escravidão na região portuária e na cidade, cujos marcos físicos foram destruídos ou soterrados durante o processo de urbanização. Atualmente, o cemitério e o Cais do Valongo permanecem expostos graças a iniciativas de lideranças negras, de agentes culturais locais e de alguns pesquisadores, com apoio de setores do poder público, com $\mathrm{o}$ intuito de trazer à tona essa história.

O valor patrimonial do cais e do cemitério reside na ideia de testemunharem crimes contra a humanidade - o tráfico transatlântico e a escravização que nunca mais devem voltar a ocorrer. $\mathrm{O}$ cais passou a denunciar o fato de o Rio de Janeiro e o Brasil terem sido respectivamente a cidade e o país que mais receberam escravizados em todo o mundo ${ }^{4}$. Para muitos ativistas negros, ele simboliza tanto o enorme preconceito racial que atravessa a sociedade brasileira quanto as lutas das lideranças negras do passado e do presente pela sua superação. Mas, acima de tudo, o cais é considerado um lugar de ancestralidade, já que por ele teriam desembarcado os africanos, os deuses e as expressões culturais que deram origem ao povo e à cultura afro-brasileiros (VASSALLO;

\footnotetext{
Estima-se que 2 milhões e 600 mil africanos escravizados tenham desembarcado no Rio de Janeiro e 4 milhões em todo o Brasil.
} 
CICALO, 2015). Essas representações trazem uma inflexão nas narrativas tanto locais quanto nacionais sobre a escravidão, apoiando-se em critérios morais que denunciam os seus nefastos efeitos no passado e no presente, como o preconceito e a desigualdade racial (VASSALLO, 2017). O cais e o cemitério dão visibilidade ao complexo escravagista do Valongo (HONORATO, 2008), que englobava os cais de desembarque de africanos, o mercado de escravos e outros locais, e que é considerado o maior das Américas.

O reconhecimento do Cais do Valongo pela Unesco incentivou e deu legitimidade a pedidos de reparação por parte de diversos coletivos negros e conferiu enorme centralidade à dimensão política da Pequena África. Assim, desde 2018 , lideranças negras se mobilizam em torno de outro cemitério de africanos escravizados, o da Igreja de Santa Rita, na atual avenida Marechal Floriano, situado a algumas centenas de metros do Cais do Valongo e da Pedra do Sal. A construção da Linha 3 do Veículo Leve sobre Trilhos (VLT), anunciada para 2018 ainda como decorrência do Projeto Porto Maravilha, implicaria obras que incluíam o local onde se encontra o cemitério. Uma equipe de arqueologia seria responsável pela prospecção arqueológica e coleta do material considerado relevante. O local teria recebido os corpos de escravizados desde o início do século XVIII até a década de 1770, quando os enterramentos foram transferidos para o Cemitério dos Pretos Novos da Gamboa. A partir de então, o campo santo foi soterrado pelo processo de urbanização da cidade e sua memória foi silenciada. Sobre o local temos hoje apenas sobrados e prédios comerciais e uma importante via asfaltada por onde circulam carros e ônibus.

A possibilidade das obras onde se encontra o cemitério mobilizou Gracy Mary, integrantes do Quilombo Pedra do Sal e do Instituto dos Pretos Novos, bem como diversas outras lideranças negras que atuam na região portuária, que criticavam o descaso com a memória afrodescendente. Para os ativistas negros, as obras representam a profanação de um espaço sagrado onde estão enterrados os seus ancestrais. Segundo eles, tanto o espaço do cemitério quanto o território mais amplo da Pequena África estão indelevelmente relacionados às suas próprias trajetórias. Trata-se de locais que carregam consigo a história dos africanos e afrodescendentes dos quais se consideram herdeiros no presente, 
daí a importância dessas memórias serem trazidas à tona. Para eles, não é mais possível que a história seja narrada apenas da perspectiva dos brancos, silenciando importantes personagens negros e eventos que lhes são relacionados. Por isso lutam para dar visibilidade às suas próprias perspectivas e para que tanto a sua voz quanto a que atribuem aos seus antepassados sejam ouvidas.

Desde que as obras do VLT foram anunciadas, essas lideranças reivindicaram reuniões com os seus principais responsáveis, como a empresa privada encarregada da construção da Linha 3, a Companhia de Desenvolvimento Urbano da Região do Porto (CDURP), a empresa de arqueologia e o Iphan. Exigiam participação ativa em todo o processo, pois em seus próprios termos querem ser sujeitos - e não mais objetos - dessa história que consideram lhes pertencer. Eles entendem que a ausência de participação de representantes negros seria mais uma expressão do preconceito racial que permeia a sociedade brasileira e que invisibiliza os protagonistas negros e suas histórias. Com esse intuito criaram a "Comissão da Pequena África", por meio da qual interagem com os representantes do poder público e da iniciativa privada e lutam para participar e serem atendidos. Parte dessas reuniões foi permeada por um ambiente de muita tensão, em que os ativistas negros tinham a nítida sensação de não terem os seus pleitos devidamente reconhecidos. Mas ao final conseguiram fazer com que o nome de três estações de VLT fosse alterado para fazer referência às memórias negras da localidade ${ }^{5}$. Também foram atendidos no pedido para que os corpos dos africanos ali enterrados não fossem escavados, coletados e examinados pela equipe de arqueologia, em sinal de respeito à sua sacralidade. Suas demandas também incluem a demarcação da área aproximada do antigo cemitério, um totem com informações históricas sobre ele e rosas negras ${ }^{6}$ em pedras portuguesas desenhadas na calçada, ações que por ora não foram realizadas.

\footnotetext{
As três estações são: Camerino-Rosas Negras; Cristiano Otoni-Pequena África; e Santa Rita-Pretos Novos.

6 Rosas Negras era o nome dado a uma comissão de mulheres que integrava a Frente Negra Brasileira importante associação de negros que existiu durante a década de 1930. Ao dar visibilidade à atuação dessa associação de mulheres negras, o movimento negro contemporâneo procura chamar a atenção para o protagonismo das mulheres negras na luta contra o preconceito racial ao longo da história.
} 
De acordo com Yedo Ferreira, reconhecido militante negro, porta-voz da Comissão da Pequena África e agora com 85 anos, trata-se do que ele chama de uma "reparação pela memória". Nesse sentido, as lutas em torno das obras do VLT são apenas parte de um projeto bem mais amplo, que se traduz no Projeto de Lei Municipal no 774/2018. Por meio dele, Yedo Ferreira e outras lideranças reivindicam a demarcação do território da Pequena África (envolvendo a parte da Zona Portuária que engloba a Pedra do Sal, o Cais do Valongo e o Cemitério de Santa Rita, dentre outras localidades), com a criação de uma subprefeitura própria que se dedique a ações de preservação e de incentivo cultural destinadas à memória da presença dos africanos escravizados na região.

Aqui, os significados da Pequena África são acrescidos das referências à escravização e atualizados pelas suas novas representações e moralidades. Esse território negro não se refere mais apenas à sociabilidade festiva dos afrodescendentes - que gira em torno de Tia Ciata e da Pedra do Sal -, mas também aos horrores cometidos durante a escravidão e às resistências negras à dominação. Se os grandes marcos temporais até então se concentravam no pós-abolição, temos um dilatamento temporal que remete aos séculos XVIII e início do XIX, período em que estavam ativos o Cemitério de Escravos de Santa Rita, o Cemitério dos Pretos Novos e o Cais do Valongo. Há também um dilatamento espacial, já que as referências à Pequena África se expandem da Pedra do Sal para os locais onde se encontram o Cemitério de Santa Rita, na atual rua Marechal Floriano, e o Cemitério dos Pretos Novos, na rua Pedro Ernesto.

Tal como Gracy Mary, esses ativistas negros tendo à frente Yedo Ferreira também estabelecem continuidades entre passado e presente. Ao declararem que os africanos enterrados nos cemitérios de escravizados são seus ancestrais, eles afirmam laços indeléveis entre os vivos e os mortos, entre si próprios e a Pequena África. Com isso, constroem vínculos primordiais com o território e reivindicam autoctonia. Ao fazê-lo, investem-se de legitimidade diante do poder público e adquirem força política para tentar fazer com que suas demandas sejam atendidas. Por meio de suas ações, as lideranças negras agem no presente e produzem uma Pequena África dotada de uma forte conotação política que se ancora nas demandas por reconhecimento e reparação. Suas 
lutas pela valorização das memórias negras dos ancestrais são também lutas contra a desigualdade racial, pelas vozes e histórias negras silenciadas e pelo protagonismo negro na contemporaneidade.

\section{JUDEUS CARIOCAS E A PEQUENA ÁFRICA}

Em 2013, um grupo de músicos denominado Rancho Praça Onze Klezmer Carioca surgiu na cena carnavalesca do Rio de Janeiro. Idealizado por Ricardo Goldfeld Szpilman 7 membro de uma família de músicos judeus, o grupo propõe misturar a música judaica tradicional do Leste Europeu, conhecida como klezmer $^{8}$, com a música brasileira. O propósito dessas hibridações criativas se fundamenta na ideia de que os imigrantes judeus estabelecidos na Praça Onze teriam convivido com os negros recém libertos e participado da formação da cultura popular carioca na primeira metade do século XX. Nosso argumento é que, ao produzir essas colagens musicais, esses músicos constroem um senso particular de ser judeu carioca, no qual a relação de permeabilidade com a população afrodescendente da Praça Onze é simultaneamente emblemática e constitutiva.

Procuramos mostrar como essa etnicidade (BARTH, 2000) é cartografada por meio da sinalização de certos lugares e marcos da presença judaica e negra na Praça Onze e seus arredores e como essa identificação, reconstituída

\footnotetext{
Músico e professor da Escola Pedro II, sede São Cristovão. É mestre em música pela Universidade Federal do Estado do Rio de Janeiro (Unirio) e organizador de importantes publicações de partituras de música judaica para coro.

8 O klezmer emergiu no contexto da vida judaica do Leste Europeu em fins da Idade Média, sob forte influência de diversos gêneros folclóricos dos Balcãs, especialmente cigano, tratando-se de uma música instrumental de caráter popular e não litúrgica ou semilitúrgica. O termo klezmer em ídiche deriva das palavras klei (instrumento) e zemer (canção). Os músicos naquele contexto, chamados klezmorim, atuavam tanto em ambientes judaicos como não judaicos. Suas performances eram mais frequentemente realizadas em cerimônias, casamentos e demais festividades comunitárias. No século XIX, o klezmer se expandiu para além dos limites do Império Otomano. As bandas eram tipicamente formadas por músicos homens e incluíam violinos, violoncelo ou contrabaixo, címbalo e flauta. Outros instrumentos como o clarinete e metais foram incorporados no século XX, já na era do disco. O klezmer sofreu profundas transformações ao longo de sua diáspora, especialmente após o Holocausto Nazista, se dispersando ao redor do mundo e passando a adquirir cores locais.
} 
por intermédio da memória imaginativa, é experienciada, repercutindo em suas subjetividades. Essas narrativas e performances (SCHECHNER, 1985; TURNER; BRUNER, 1986) se fundamentam na valorização do passado e na busca de uma (re)vinculação com origens culturais imaginadas, relativas tanto a uma herança cultural judaica do Leste Europeu, quanto afrodescendente e carioca. Em outras palavras, estes judeus sentem-se tanto como herdeiros do universo dos shtetls do velho mundo, como do caldo cultural da chamada Pequena África. Os shtetls são pequenas cidades ou vilarejos em que os judeus do Leste Europeu, em sua maioria, residiam. Situavam-se em certas áreas do Império Russo, Reino da Polônia, Galícia e România, fora dos quais, geralmente, sua permanência era proibida. Sua emergência resultou basicamente da exclusão social dos judeus da sociedade na Rússia Czarista e na Europa Oriental. A vida dos judeus nesses lugares é frequentemente descrita como extremamente difícil, na qual se passava fome e frio, embora ela também seja alvo de representações românticas e nostálgicas como as que foram veiculadas pela pintura de Marc Chagall, que busca valorizar um modo de vida tradicional. É interessante observar que tanto esses vilarejos quanto a Pequena África foram lugares que abrigaram uma população submetida a forte segregação social.

Com o gradual aumento dos ataques aos shtetls, sua população começou a emigrar. A chegada de imigrantes judeus na cidade do Rio de Janeiro aumentou significativamente desde o final do século XIX, vindos dos mais diversos lugares, mas especialmente da Europa Central e Oriental, Península Ibérica, Oriente Médio e Norte da África. A maior parte desses imigrantes se estabeleceu na área central, distribuídos em sub-regiões, de acordo com a origem étnica ou nacional. Enquanto os ashkenazim ${ }^{9}$ se fixaram na região da Praça Onze, os sefaradim ${ }^{10}$ se estabeleceram majoritariamente nas imediações da Rua da Alfândega, onde, desde os anos 1960, organizou-se a Sociedade de Amigos das Adjacências da Rua da Alfândega (Saara), um grande e importante centro comercial (RIBEIRO, 2013).

\footnotetext{
9 Judeus da Europa Central e Oriental.

${ }^{10}$ Judeus da Península Ibérica e Norte da África.
} 
Os judeus da Cidade Nova instalaram-se nas ruas próximas à antiga Praça Onze de Junho, anteriormente denominada Largo do Rocio Pequeno, num conjunto de ruas e vilas de casas. Dentre essas vilas, destaca-se a Villa Dr. Alberto Sequeira, localizada na rua Clementino Fraga, conhecida como Vila do Éden ou, ainda, Ídiche Avenid, em referência ao ídiche, língua amplamente compartilhada pelos judeus ashkenazim. Esses imigrantes desenvolveram uma significativa atividade cultural, social, econômica, religiosa e política (FRIDMAN, 2007). Havia na região diversos templos religiosos, clubes, jornais, agremiações, organizações políticas e lojas de produtos judaicos.

A Praça Onze foi fundamentalmente o local de residência de uma população que ocupava os mais baixos extratos da população. Trata-se de uma ampla classe de trabalhadores pobres que exerciam ocupações pouco especializadas. Fridman nota, também, que essa região da cidade, pelas características de suas moradias precárias e da forte presença de população imigrante, tornou-se marginal aos olhos do Estado. De fins do século XIX a meados do século XX, uma série de intervenções por parte do Estado alterou drasticamente a área central da cidade, orientadas por padrões europeus de civilidade. As primeiras reformas ocorreram durante a gestão do prefeito Pereira Passos (1903-1906), quando houve uma ampla eliminação de moradias populares, que acabou por nomear a administração pública de "bota-abaixo" (FRIDMAN, 2007). Foi, porém, a partir de 1937 que novas intervenções ganharam impulso, resultando na abertura da imponente avenida Presidente Vargas. A Praça Onze de Junho, juntamente com algumas ruas e seu casario foram destruídas, coincidindo com o período de deslocamento dos judeus e de outros grupos para outras áreas da cidade. Estas intervenções tiveram consequências dramáticas para grande parte dos diversos grupos que ali viviam, desarticulando modos de vida de grupos étnicos considerados perigosos e indesejáveis (FRIDMAN, 2007).

Embora a Praça Onze de Junho tenha desaparecido fisicamente, seu nome continua a ocupar um lugar crucial no imaginário sobre a região central e particularmente sobre a Pequena África. Assim, do mesmo modo, o chamado bairro judeu não mais existe concretamente, mas permanece de modo vivo na memória de seus antigos residentes. A passagem dos judeus pela região, de 
fato, não deixou muitas marcas físicas e nota-se que estes se estabeleceram em outras espacialidades da cidade por volta dos anos 1940. Os estabelecimentos comerciais, restaurantes, associações, sinagogas do bairro judeu desapareceram ao longo dos processos de reurbanização. Por outro lado, essa presença é imaginariamente reelaborada de diversas formas. A recente descoberta, por este grupo de músicos, da existência da Villa Dr. Alberto Sequeira, onde viveram, inclusive, parentes de alguns de seus membros, teve um impacto importante na reconstrução dessa memória. Até bem pouco tempo, um judeu septuagenário de origem russa, chamado Maurício Bemkes, conhecido como Pinduca, vivia na casa de número 49 com dois filhos. Casado com uma negra chamada Celi, Pinduca testemunhou grande parte da intensa vida judaica e as radicais intervenções realizadas na região. Pinduca, a quem foi atribuído o título de "o último judeu da Praça Onze"11, era uma figura muito popular e carismática. Sua casa vivia rodeada de parentes, vizinhos e amigos que habitualmente se juntavam para alguma comemoração. Pinduca é um emblema desse quase lendário encontro afro-judaico na Praça Onze. Realidade e imaginação certamente se misturam nas inúmeras versões desses intercâmbios, mas é possível dizer que houve solidariedade entre os grupos pela proximidade momentânea de suas situações socioeconômicas.

A vila tornou-se um "lugar de memória" (NORA, 1993) para os músicos do rancho que passaram a visitá-la periodicamente, seja para conversar com Pinduca e sua família ou mesmo para tocar. Diversas performances do grupo tiveram lugar na vila em torno da casa de Pinduca, em momentos de forte congraçamento.

O interesse por esse fragmento de história da vida judaica na Praça Onze e do encontro de judeus e negros nesse território é um dos motores da atividade musical do Rancho. O grupo tem aproximadamente 14 músicos e é formado majoritariamente por judeus não ortodoxos entre 40 e 60 anos de idade. Há também uma presença menos permanente de jovens e idosos, além de não judeus, o que tem sido apontado como um fator importante. Em todo

\footnotetext{
${ }_{11}$ Ver filme Samba com pretzel: $o$ último judeu da Praça Onze, de Rose Esquenazi e Bernardo Tabak. Disponível em: https://bit.ly/2GB2Gki. Acesso em: 24 jan. 2019.
} 
caso, é a terceira geração descendente desses emigrados que compõe a maior parte do grupo.

Nessa direção, os membros do Rancho procuram valorizar as formas expressivas que emergiram do contexto da Praça Onze e da Pequena África, de modo mais amplo e, em particular, o samba, o maxixe, a marcha de carnaval e congêneres. A relação de proximidade espacial com a Tia Ciata e outras baianas é bastante valorizada, o que se pode constatar a partir da presença da imagem desta figura no centro do estandarte do grupo, rodeada por antigas fotografias de parentes judeus de alguns de seus membros. Nesse sentido, a própria relação de vizinhança é ainda reforçada nessas narrativas com a indicação de endereços judeus adjacentes à mítica casa de Tia Ciata, localizada na antiga rua Visconde de Itaúna, onde muitos judeus mantinham estabelecimentos comerciais e residências. Segundo Fridman (2007), no número 203 daquela rua, localizava-se o Iughend Bund (Clube Israelita Juventude) e, no número 151, a Pensão de Sarah e Jaime Velger. Havia ainda a biblioteca judaica Bialik que dividia o mesmo sobrado com a gafieira Kananga do Japão. Antigos moradores relatam que os judeus frequentavam estes locais de lazer, incluindo bares, cafés, cervejarias e sinucas, embrenhando-se com outras categorias sociais.

O Rancho tem realizado arranjos musicais, ensaios e apresentações públicas com o propósito de valorizar o que concebem como patrimônio histórico, cultural e arquitetônico legado pela presença judaica e negra na Praça Onze. Szpilman criou o neologismo sambahoire como expressão dessas bricolagens musicais, em que hoire ${ }^{12}$ designa uma dança de roda fortemente presente num amplo espectro de culturas, incluindo a judaica. Ademais, uma parte do repertório de klezmer consiste em músicas instrumentais de caráter festivo e alegre, conhecidas como freilachs e que, originalmente, eram executadas em contextos comemorativos, como casamentos e bar mitzvás ${ }^{13}$. Alguns membros do grupo cultivam a ideia de que o klezmer tem um espírito muito próximo da música popular carioca, com seus toques de informalidade, improviso e virtuosismo.

\footnotetext{
${ }_{12}$ Termo de origem grega que significa círculo. Refere-se a um grupo de danças compartilhadas por diversas culturas.

${ }^{13}$ Bar Mitzvá é a cerimônia que insere o jovem judeu como adulto na comunidade judaica.
} 
Szpilman conta que teve a ideia de criar o grupo ao revisitar as partituras herdadas de seu avô Samuel Szpilman ${ }^{14}$, violinista e saxofonista de uma importante família de músicos poloneses. O músico define o grupo como uma orquestra popular composta por um naipe de violinos, sopros, violão, cavaquinho, baixo acústico, tuba, acordeão, escaletas e percussão. Ao longo do tempo, entretanto, outros instrumentos têm se juntado à orquestra.

Uma parte fundamental da atividade do grupo consiste em elaborar arranjos para temas musicais judaicos, sendo a maioria elaborada por Szpilman, que também compõe para o Rancho. O trabalho envolve uma particular sensibilidade na combinação do tema com algum gênero musical brasileiro. Assim, uma pulsação de samba ou choro pode ser agregada a um tema ou canção, obtendo-se um resultado original. A sensibilidade aqui reivindicada é aquela que permite perceber nuances do tema e similaridades com gêneros brasileiros. É assim que um afoxé ou uma ciranda podem ser mobilizados para alguns destes arranjos criativos, revestindo o repertório klezmer de determinadas cores locais.

Outro aspecto interessante dessas performances é a adoção, pelo grupo, de uma indumentária própria que remeteria à ambiência da histórica Praça Onze e aos seus "carnavais democráticos". Assim, há uma ênfase muito particular no uso de acessórios, tais como boinas, chapéus e suspensórios, camisa social etc. A ideia aqui, mais uma vez, é buscar uma síntese na produção dessa caracterização que combine traços de personagens que povoaram a paisagem da Praça Onze no princípio do século XX. Com base nessas descrições, sugerimos que todas estas ações visam "objetificar" (HANDLER, 1985) o passado da Praça Onze e a própria Pequena África. Richard Handler definiu o conceito de objetificação cultural como uma tendência tipicamente ocidental e moderna de dar concretude a noções imateriais, como o tempo.

Parece bastante evidente que a experiência vivida por este grupo mobiliza aspectos subjetivos de suas identidades étnicas e sociais. O que parece estar em

\footnotetext{
${ }^{14}$ Samuel e seus irmãos, Moysés e Waldemar, chegaram ao Rio de Janeiro em 1924, de Ostrowicz, Polônia e mais tarde integraram a primeira formação da Orquestra Sinfônica Brasileira. Dedicaram-se à música erudita e ao klezmer, atuando em diversos contextos relacionados à comunidade judaica carioca, especialmente em festividades de casamento e bar mitzvás.
} 
jogo para esses músicos é a dupla necessidade de reconhecer uma diferença étnica específica e, ao mesmo tempo, almejar certo grau de assimilação à cultura brasileira. Essa etnicidade específica mobiliza fortes representações sobre lugares, regiões da cidade e o passado da vida judaica e negra na Praça Onze e no Leste Europeu. Tal como Michel Agier (2011) sugeriu, as identidades não devem ser tomadas como substâncias, essências. O autor observa que elas são sempre relativas e que "as fronteiras das cidades não são nem mais verdadeiras nem menos construídas que as da etnicidade" (AGIER, 2011, p. 70-71). Nessa direção, os membros desse grupos musical, de certo modo, sublinham a positividade da permeabilidade social como um traço da sociabilidade carioca que contribuiria para o estabelecimento dos judeus na cidade, de forma mais harmoniosa. Como Szpilman certa vez mencionou, essa prática musical pode contribuir para que os judeus sejam percebidos com menos estranheza e para que se possa dirimir o preconceito racial. Em tempos de recrudescimento, em muitas partes do mundo, de regimes conservadores e autoritários e, particularmente, do antissemitismo, é preciso reconhecer que esta ação é, no mínimo, louvável e bem vinda.

\section{CONCLUSÃO}

Nesse artigo, partimos da perspectiva de que a Pequena África - como os demais territórios urbanos - não possui definições a priori, mas sim significados múltiplos que podem ser declinados de diversas maneiras. Nos propomos aqui a perceber alguns dos sentidos acionados por lideranças negras e judeus cariocas que a presentificam na contemporaneidade, num momento em que seu território adquire nova centralidade devido às recentes reformas urbanísticas. Dependendo dos atores em jogo, do contexto sócio-histórico e das situações observadas, os significados da Pequena África podem estar mais relacionados ao mundo do trabalho, das festas e das religiões afrodescendentes; ao crime contra a humanidade que foi a escravização e o tráfico transatlântico negreiro e suas formas de resistência; ou a um local de moradia e convívio de 
judeus, negros e outros grupos étnico-raciais que ali compartilhavam certas experiências de pobreza e marginalidade. Do mesmo modo, seu simbolismo pode estar mais concentrado no espaço físico da Pedra do Sal, nos vestígios do local que no passado abrigou a Praça Onze, ou ainda se expandir para o território da atual avenida Marechal Floriano, onde se encontra a Igreja de Santa Rita e o Cemitério de Escravizados. Em termos temporais, observamos que o imaginário em torno desse território negro pode tanto privilegiar o período do pós-abolição quanto recuar no tempo para incorporar o momento de intensificação e ápice do tráfico transatlântico negreiro, indo do século XVIII às primeiras décadas do XIX. Assim, podemos concluir que a Pequena África é socialmente construída e, por isso mesmo, é também multivocal, pois é perpassada por diferentes vozes e significados.

Pretendemos mostrar que, ao performatizar a Pequena África, esses indivíduos e grupos entrelaçam as suas próprias ações e trajetórias às narrativas que constroem sobre a cidade e, ao fazê-lo, reconstroem o espaço urbano e a si próprios no mesmo movimento. Produzem a localidade Pequena África ao mesmo tempo em que se produzem como sujeitos dessa história, imprimindo as suas próprias marcas no território e no seu imaginário.

Pudemos observar como, por meio da reivindicação de vínculos primordiais com a Pequena África, lideranças negras buscam não apenas trazer as memórias silenciadas de africanos e seus descendentes, mas também, simultaneamente, construir novas formas de subjetividade e de participação. Organizam-se por meio de uma ação política que visa tanto o reconhecimento da importância da presença negra na cidade quanto a reparação pelos crimes e outras formas de exclusão cometidos contra eles. Nesse processo, reelaboram os sentidos da Pequena África, incorporando perspectivas atuais sobre gênero e raça, bem como a nova moralidade produzida sobre a escravização.

Os músicos judeus do Rancho Praça Onze Klezmer Carioca, por sua vez, reivindicam e celebram a Pequena África como um lugar de encontros entre grupos que compartilhavam a mesma situação de pobreza e exclusão social - sobretudo judeus e negros - e congraçavam em torno de suas ricas expressões culturais. Ao mesclar símbolos característicos das culturas judaica 
e afro-brasileira em suas performances musicais, produzem uma identidade no presente: a de judeus cariocas cujas origens baseiam-se tanto em referências judaicas quanto em locais, acontecimentos e personagens considerados centrais para a formação da cultura popular carioca. Assim, afirmam um duplo pertencimento, ao mesmo tempo judeu e carioca, procurando equilibrar-se nessa tênue e difícil fronteira entre marcar diferenças e enfatizar porosidades e permeabilidades. Por outro lado, celebrar os hibridismos que estão na base das construções identitárias e culturais também remete a um posicionamento contra o preconceito e a discriminação racial.

Com isso, os indivíduos e grupos aqui abordados elaboram narrativas não hegemônicas que trazem à tona a presença negra e escrava na região portuária, assim como a judaica e ainda outras tantas, bem como as suas vinculações com o contexto presente das reformas urbanísticas e da luta contra o preconceito racial. Em todas essas situações, o passado é acionado para se falar do presente e, mais do que isso, para se agir no presente.

\section{REFERÊNCIAS}

1. AGIER, Michel. Antropologia da cidade: lugares, situações, movimentos. São Paulo: Terceiro Nome, 2011.

2. APPADURAI, Arjun. Modernity at large: cultural dimensions of globalization. Minneapolis: University of Minnesota Press, 1996.

3. BARTH, Fredrik. Grupos étnicos e suas fronteiras. In: BARTH, Fredrik; LASK, Tomke (orgs.). O Guru, o iniciador e outras variações antropológicas. Rio de Janeiro: Contra Capa, 2000. p. 27-50.

4. BIOGRAFIA. Casa da Tia Ciata, Rio de Janeiro, 18 maio 2010. Disponível em: https://bit.ly/2UWE4LK. Acesso em: 23 abr. 2019.

5. BRASIL. Ministério da Cultura. Conferência Mundial contra o Racismo, Discriminação Racial, Xenofobia e Intolerância Correlata, 31 ago.- 8 set, 2001, Durban. Brasília, DF: Ministério da Cultura, 2001. Disponível em: https://bit. ly/1Nuu8xC. Acesso em: 2 ago. 2017. 
6. CAMINHOS de Ciata. Casa de Tia Ciata, Rio de Janeiro, 1 out. 2015. Disponível em: https://bit.ly/2GAYJff. Acesso em: 12 jan. 2019.

7. CARVALHO, Bruno. Porous city: a cultural history of Rio de Janeiro (from the 1810s Onward). Liverpool: Liverpool University Press, 2013.

8. CORTEJO da Ciata. Casa de Tia Ciata, Rio de Janeiro, 20 nov. 2018. Disponível em: https://bit.ly/2GnnHNO. Acesso em: 12 jan. 2019.

9. CULTNE DOC: Santa Rita Pretos Novos - Linha 3 - VLT carioca. 8'42". Cultne Acervo. YouTube. 2018. Disponível em: https://bit.ly/2vjHlFz. Acesso em: 10 jan. 2019.

10. FRIDMAN, Fania. Paisagem estrangeira: memórias de um bairro judeu no Rio de Janeiro. Rio de Janeiro: Casa da Palavra, 2007.

11. GONÇALVES, Renata de Sá. Cronistas, folcloristas e os ranchos carnavalescos: perspectivas sobre a cultura popular. Estudos Históricos, Rio de Janeiro, v. 2, n. 32, p. 89-105, 2003.

12. GONÇALVES, Renata de Sá. Eu sou o samba: sobre lugares, pessoas e pertencimento. Sociedade e Cultura, Goiânia, v. 16, n. 1, p. 107-117, jan.-jun. 2013.

13. GRIN, Monica. Ambiguidades do multiculturalismo no Brasil: diálogos entre negros e judeus. WebMosaica, Porto Alegre, v. 1, n. 1, p. 82-93, jan.-jun. 2009.

14. GUIMARÃES, Roberta Sampaio. A utopia da Pequena África: projetos urbanísticos, patrimônios e conflitos na Zona Portuária carioca. Rio de Janeiro: FGV Editora, 2014.

15. HANDLER, Richard. On having a culture. In: STOCKING Jr., George W. (org.). Objects and others: essays on museums and material culture. Madison: University of Wisconsin Press, 1985. p. 192-217.

16. HONORATO, Cláudio de Paula. Valongo: o mercado de escravos do Rio de Janeiro, 1758 a 1831. Dissertação (Mestrado em História) - Instituto de Ciências Humanas e Filosóficas, Universidade Federal Fluminense, Niterói, 2008.

17. INSTITUTO ESTADUAL DO PATRIMÔNIO CULTURAL. Processo de Tombamento da Pedra do Sal no 300048, de 2 de maio de 1984. Rio de Janeiro: Inepac, 1984.

18. MATTOS, Hebe; ABREU, Martha. Relatório histórico-antropológico sobre o Quilombo da Pedra do Sal: em torno do samba, do santo e do porto. In: O’DWYER, Eliane Cantarino (org.). O fazer antropológico e o reconhecimento de direitos constitucionais. $\mathrm{O}$ caso das terras de quilombo no estado do Rio de Janeiro. Rio de Janeiro: E-papers, 2012. p. 23-63. 
19. MOURA, Roberto. Tia Ciata e a Pequena África no Rio de Janeiro. 2. ed. Rio de Janeiro: Secretaria Municipal de Cultura, 1995.

20. MULTIPLICANDO saberes na casa de Tia Ciata. 2'. Casa Tia Ciata. YouTube. 2018. Disponível em: https://bit.ly/2IAmBBZ. Acesso em: 12 jan. 2019.

21. NORA, Pierre. Entre memória e história: a problemática dos lugares. Projeto História, São Paulo, v. 10, p. 7-28, 1993.

22. POLLAK, Michael. Memória e identidade social. Estudos Históricos, Rio de Janeiro, v. 5, n. 10, p. 200-212, 1992.

23. RIBEIRO, Paula. Cultura urbana e etnicidade no Rio de Janeiro do século XX: imigrantes árabes e judeus no Saara e na Praça Onze. Revista Eletrônica do NIEJ, Rio de Janeiro, v. 4, p. 59-68, 2013.

24. RODMAN, Margaret. Empowering place: multilocality and multivocality. In: LOW, Setha M.; LAWRENCE-ZUNIGA, Denise. The anthropology of space and place: locating culture. Hoboken: Wiley-Blackwell, 2008.

25. SCHECHNER, Richard. Between theater and anthropology. Philadelphia: University of Pennsylvania Press, 1985.

26. SOARES, Mariza de Carvalho. Nos atalhos da memória: monumento a Zumbi. In: KNAUSS, Paulo (org.). A cidade vaidosa. Imagens urbanas do Rio de Janeiro. Rio de Janeiro: SetteLetras, 1999. v. 1, p. 117-135.

27. TURNER, Victor; BRUNER, Edward (eds.). The anthropology of experience. Champaign: University of Illinois Press, 1986.

28. VASSALO, Simone Pondé. Interventions urbaines et processus de patrimonialisation: la construction d'un territoire noir dans la zone portuaire de Rio de Janeiro (1980-2000). In: CAPONE, Stefania; MORAIS, Mariana Ramos de (eds.). Afro-patrimoines: culture afro-brésilienne et dynamiques patrimoniales. Paris: Lahic; CNRS, 2015. p. 139-161.

29. VASSALLO, Simone Pondé. Entre vidas objetificadas e vítimas da escravidão: a trajetória das ossadas do Cemitério dos Pretos Novos, no Rio de Janeiro. Sexualidad, Salud y Sociedad, Rio de Janeiro, n. 25, p. 277-297, 2017. Disponível em: https:// bit.ly/2GzuoOm. Acesso em: 22 abr. 2019.

30. VASSALLO, Simone Pondé; CICALO, André. Por onde os africanos chegaram: o Cais do Valongo e a institucionalização da memória do tráfico negreiro na região portuária do Rio de Janeiro. Horizontes Antropológicos, Porto Alegre, ano 21, n. 43, p. 239-271, jan.-jun. 2015. 